\title{
News, sovereign debt maturity, and default risk*
}

\author{
Maximiliano Dvorkin \\ Juan M. Sánchez \\ Horacio Sapriza \\ Emircan Yurdagul \\ FRB of St. Louis \\ FRB of St. Louis \\ Federal Reserve Board \\ Universidad Carlos III
}

October 31, 2018

\begin{abstract}
Leading into a debt crisis, interest rate spreads on sovereign debt rise before the economy experiences a decline in productivity, suggesting that news may play an important role in these episodes. The empirical evidence also shows that a news shock has a significantly larger contemporaneous impact on sovereign credit spreads than a comparable shock to labor productivity. We develop a quantitative model of news and sovereign debt default with endogenous maturity choice that generates impulse responses very similar to the empirical estimates. The model allows us to interpret the empirical evidence and to identify key parameters. We find that, first, the increase in sovereign yield spreads around a debt crisis episode is due mostly to the lower expected productivity following a bad news shock, and not to the borrowing choices of the government. Second, a shorter debt maturity increases the chance that bad news shocks trigger a debt crisis. Third, an increase in the precision of news allows the government to improve its debt maturity management, especially during periods of high financial stress, and thus face lower spreads and default risk while holding the amount of debt constant.
\end{abstract}

JEL Classification: F34, F41, G15.

Keywords: Crises, News, Default, Spreads, Maturity, Country Risk, Sovereign Debt.

\footnotetext{
${ }^{*}$ The views expressed in this paper are those of the authors and do not necessarily reflect those of the Federal Reserve Bank of St. Louis, the Board of Governors, or the Federal Reserve System. We thank Yan Bai, Mark Bils, Luca Dedola, Juan Carlos Hatchondo, Fernando Leibovici, Gabriel Mihalache, Alex Monge-Naranjo, Paulina Restrepo-Echevarria, and seminar and conference participants for useful conversations and comments. Ryan Mather provided excellent research assistance. Yurdagul gratefully acknowledges the support from the Ministerio de Economía y Competitividad (Spain) (ECO2015-68615-P), María de Maeztu grant (MDM 2014-0431), and from Comunidad de Madrid, MadEco-CM (S2015/HUM-3444).
} 


\section{Introduction}

The European financial crisis has highlighted how shifts in expectations about the future path of the economy affect sovereign debt decisions and prices, reinforcing the view that news about future fundamentals are a highly relevant driving force in international credit markets. Our paper analyzes the extent to which changes in expectations driven by news matter for country risk dynamics, and how the effect depends on the maturity of sovereign debt. ${ }^{1}$

The role of news about future productivity for sovereign credit events is illustrated in Figure 1. The plots in the figure show the evolution of labor productivity and country risk measured by the EMBI+ around events of sovereign financial distress. ${ }^{2}$ The sample contains 20 years of data for 12 emerging economies. The analysis focuses on episodes involving significantly high country risk. ${ }^{3}$ The main takeaway from the figure is that country risk reacts prior to any sharp reduction in labor productivity, suggesting that bond prices may be responding to news about future productivity.

To complement the suggestive evidence provided by the plots with a more formal empirical analysis, we estimate a panel-VAR following the identification strategy of news shocks introduced by Beaudry and Portier (2006). Our results show that news shocks have a significant contemporaneous effect on country risk, and that such effect is larger than that of a labor productivity shock of similar magnitude.

We take these findings as a motivating starting point, and we advance our analysis further by developing a structural model with news, debt maturity, and default risk. ${ }^{4}$ Thus, a key contribution of our study is to provide a structural interpretation of the empirical findings using a quantitative dynamic small open economy model of sovereign debt, maturity, and default, subject to both contemporaneous and news shocks on labor productivity. Our setup considers

\footnotetext{
${ }^{1}$ In this paper, country risk is the risk that a government will default on its debt commitments.

${ }^{2}$ The Emerging Market Bond Index Plus (EMBI+) is a JP Morgan index of dollar-denominated sovereign bonds that tracks total returns for traded external debt instruments issued by a selection of emerging market economies.

${ }^{3}$ We define a debt crisis, or high country risk event, as a period in which the EMBI+ doubles relative to the previous year.

${ }^{4} \mathrm{~A}$ number of studies have identified potential issues with the strategy of Beaudry and Portier (2006), as summarized in the survey by Beaudry and Portier (2014).
} 
Figure 1: Labor productivity and country risk (EMBI+) at times of distress
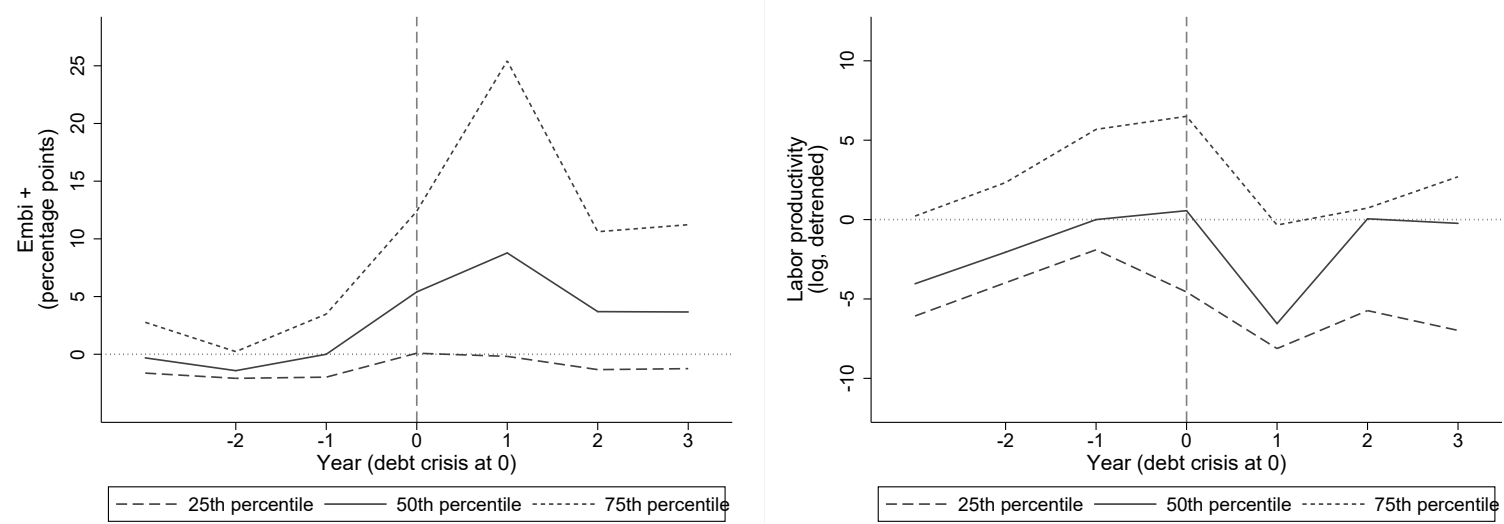

Note: Authors' calculation using yearly data from the International Labor Organization and The World Bank for Argentina, Brazil, Colombia, Ecuador, Mexico, Panama, Peru, Philippines, Russia, Turkey, Venezuela, and South Africa. Labor productivity is in logs, in deviations from a country-specific log-linear trend, and multiplied by 100. Debt crisis defined as the period in which the EMBI+ doubles relative to the previous year. The values for EMBI+ and labor productivity are normalized to those of the year before the debt crisis for the median country in the sample.

an economy that every period receives a shock to productivity, as well as a noisy signal about productivity next period, i.e., a news shock. Households value private consumption, and the benevolent government in the economy borrows from abroad to smooth consumption fluctuations. Foreign lenders charge a risk premium that accounts for the default risk they face, so interest rate spreads reflect the time-varying sovereign default risk.

The calibrated model mimics the indebtedness, default, and debt restructuring features documented for emerging countries. Our framework also captures key moments of the debt profile of these economies, such as the level and dynamics of debt duration and maturity, and the fluctuations and level of spreads for different debt maturities. Finally, the quantitative model generates dynamics of key variables around default episodes similar to those in Mendoza and Yue (2012).

Our work focuses heavily on the dynamics of debt and default risk measures leading to sovereign debt crises. Therefore, we compare the impulse responses of the model with empirical estimates. For this purpose, we estimate a structural panel-VAR using data for emerging market economies, and we show that the impulse responses to labor productivity and news shocks from the VAR and the quantitative default model are very similar. 
The quantitative model provides a tool to interpret our empirical findings. We show that in the model, given a current level of debt, income, and debt maturity, a change in news about future labor productivity can reverse the decision of the country from repayment to default. Importantly, we show that this effect weakens with higher sovereign debt maturity, as the economy is less vulnerable to debt rollover risk.

The impulse responses from the model show that the effect of negative news on spreads is much larger for 1-year than for 10-year debt instruments, leading to a reversal in the yield spread curve. The reversal of the spread curve is a key feature of several sovereign debt crisis. ${ }^{5}$ The model allows to tease out the role of news vs. government choices in driving such debt price action, showing that the increase in sovereign yield spreads around a debt crisis episode is due mostly to the lower expected productivity following a bad news shock, and not to the borrowing choices of the government. We also use the model to present impulse responses for variables other than credit spreads, where our primary finding is that negative news leads to a reduction in debt and duration.

Finally, another important contribution of our work is the study of the role of news' precision on the management of sovereign debt. We find that allowing the country to choose its debt maturity is a key component of the analysis, and we show that as news precision increases, the sovereign manages debt maturity more intensively and spreads decrease, especially during times of distress.

\subsection{Related literature}

Our paper is related to two strands of the literature. First, we borrow from the news and learning literature. Cochrane (1994) and Beaudry and Portier (2006) find that news about total factor productivity or stock prices can explain a significant portion of the forecast variance of consumption, output, and hours. Building on the real business cycle literature, Jaimovich and Rebelo (2008, 2009) and Schmitt-Grohe and Uribe (2012) explore the importance of news using log-linear approximation methods. Recently, Kamber et al. (2017) have analyzed the effect of news about

\footnotetext{
${ }^{5}$ See for instance, Neely (2012), who discusses how the Greek spread curve reversed in the years leading into the debt crisis.
} 
future TFP shocks in four advanced small open economies subject to financial frictions. However, these studies abstract from equilibrium default, a salient feature of emerging markets, and rely on log-linear approximation methods that are not well suited to address nonlinear events like debt crises. In addition, Zeev et al. (2017) analyze the effects of terms-of-trade shocks and news about them on emerging countries. ${ }^{6}$ In contrast to these papers, we focus on how news shocks in emerging economies interact with default risk and debt maturity. We consider a dynamic stochastic quantitative model of endogenous sovereign debt maturity and default, and employ nonlinear methods, which are crucial in capturing the movements in default risk and spreads as they relate to the likelihood of future income or productivity falling below a threshold.

Second, our analysis borrows from the literature on sovereign debt and default. Following the seminal work on international sovereign debt by Eaton and Gersovitz (1981), a large portion of the literature on quantitative models of sovereign debt default has used only one-period debt (Aguiar and Gopinath, 2006; Arellano, 2008; Cuadra et al., 2010; Mendoza and Yue, 2012; Yue, 2010, among others). Models of long debt duration, such as Chatterjee and Eyigungor (2012) and Hatchondo and Martinez (2009), feature exogenous maturity. In contrast, our quantitative model features endogenous sovereign debt maturity and repayment. Only recent work on quantitative default models allows for endogenous debt maturity, and it does not consider the role of news shocks (Arellano and Ramanarayanan, 2012; Bai et al., 2014; Hatchondo et al., 2016). We use the tractable endogenous maturity framework developed in Sánchez et al. (2018) and solve the model numerically using the techniques proposed by Dvorkin et al. (2018).

A related paper that incorporates news shocks in a sovereign default model is Durdu et al. (2013). The contribution of that study is to link news' precision with the level of development of the country, and to compare some predictions of the model with data as the precision of news varies. Instead, our focus is on the dynamics created by news shocks relative to productivity shocks. Nevertheless, our last section also analyses the role of the precision of news and complements Durdu et al. (2013) by showing how duration, maturity, and the term structure of interest rates are affected by the precision of news. Hence, our analysis in that section focuses on features that are not considered in Durdu et al. (2013) because in their model the country

\footnotetext{
${ }^{6}$ See also Schmitt-Grohe and Uribe (2018).
} 
can issue only one-period debt. Therefore, to our knowledge, our paper presents the first effort to integrate news about future fundamentals, endogenous debt maturity and default risk in a nonlinear dynamic stochastic quantitative model.

The rest of the paper is organized as follows. Section 2 uses a VAR to identify the effects of news on sovereign default risk. Section 3 presents the economic environment and the theoretical framework. Section 4 presents the model's calibration and compares key non-targeted moments from the model with data. Section 5 studies the response of model variables to news shocks and shows that in our model bad news may generate a debt crisis. Section 6 argues that debt management improves as the precision of news increases. Finally, Section 7 concludes.

\section{Empirical Evidence}

Our starting point is an empirical analysis on the effects of news shocks that follows the seminal work of Beaudry and Portier (2006). ${ }^{7}$ News about the future path of productivity has an impact on economic conditions today, which is typically reflected in the contemporaneous behavior of financial variables. For an emerging economy that borrows in international markets, future productivity has important effects on the current and future default decisions. Thus, emerging market interest rates typically react to productivity news.

Our analysis deviates from Beaudry and Portier (2006) in two important ways. First, we focus on emerging market economies. We use a multi-country panel data approach to overcome limitations with data availability and increase the number of observations and the precision of our estimates. In contrast, the study of Beaudry and Portier (2006) analyzes the U.S. economy. Second, we look at sovereign borrowing costs, which in the data are captured by the Emerging Markets Bond Index Plus (EMBI+) spread. In contrast, Beaudry and Portier (2006) look at movements in domestic stock market prices due to news.

Our identification strategy relies on short-run restrictions to the effects of news. Let $\epsilon_{1, t}$ denote the conventional innovation to productivity and $\epsilon_{2, t-j}$ denote the news shock, which

\footnotetext{
${ }^{7}$ Other papers have also contributed to the recent literature on news shocks. See for example, Jaimovich and Rebelo (2009); Barsky and Sims (2011); Schmitt-Grohe and Uribe (2012); Kurmann and Otrok (2013); Levchenko and Pandalai-Nayar (2015), among others.
} 
anticipates the movements in productivity $j$ periods in advance. Let $A_{t}$ denote the state of $(\log )$ productivity at time $t$, and assume that the productivity depends on current and past values of these economic shocks, i.e.,

$$
A_{t}=\left[B_{11}(L) B_{12}(L)\right]\left[\begin{array}{c}
\epsilon_{1, t} \\
\epsilon_{2, t}
\end{array}\right],
$$

where the notation follows Barsky and Sims (2011). $B_{11}(L)$ and $B_{12}(L)$ are polynomials in the lag operator. The main restriction derived from the theory is $B_{12}(0)=0$. Therefore, news shocks do not have a contemporaneous impact on productivity. A simple process that describes the effect of these shocks on productivity is

$$
A_{t}=\rho A_{t-1}+\sigma_{1} \epsilon_{1, t}+\sigma_{2} \epsilon_{2, t-j}
$$

This is a special case of equation (1), and shows that the innovation $\epsilon_{1, t}$ is able to affect productivity contemporaneously, while the innovation $\epsilon_{2, t}$ cannot, but its impact on productivity, while known today, will be realized in the future. This second type of innovation is what the literature has labeled a news shock.

We aim to identify the effect of news shocks on interest rate spreads and productivity in emerging market economies. For this purpose, we estimate a VAR system that includes measures of these two variables. In particular, we use the EMBI+ spread and labor productivity. ${ }^{8}$ Our data set consists of quarterly data from 1995q1 to 2016q4 for eight developing countries: Argentina, Brazil, Colombia, Ecuador, Mexico, Peru, Philippines, and South Africa. The sample is very similar to the one used by Uribe and Yue (2006), but is extended to include more recent years. ${ }^{9}$

\footnotetext{
${ }^{8}$ We measure the EMBI+ spread in percentage points and labor productivity in logs and in deviations from a log-linear trend, multiplied by 100. We obtain the EMBI+ and the labor productivity data from the World Bank and the International Labor Organization, respectively. Labor productivity is measured at the yearly frequency, so we obtain quarterly measures using the proportional Denton method and the country's GDP as the high frequency proxy.

${ }^{9}$ The data availability for the EMBI+ spread limits the sample of countries.
} 
The VAR system of order one can be written in reduced form as

$$
\left[\begin{array}{c}
A_{t} \\
r_{t}
\end{array}\right]=C_{0}+C_{1}\left[\begin{array}{c}
A_{t-1} \\
r_{t-1}
\end{array}\right]+\left[\begin{array}{l}
u_{1, t} \\
u_{2, t}
\end{array}\right] \text {, }
$$

where $A_{t}$ is labor productivity, $r_{t}$ is the EMBI+ spread, and $u_{1, t}$ and $u_{2, t}$ are the reduced-form disturbances. $C_{0}$ and $C_{1}$ are matrices of coefficients. Following Uribe and Yue (2006), we allow $C_{0}$ to vary by country in our panel -i.e., a country fixed-effect- and we estimate the system equation-by-equation employing the instrumental-variable method they use for dynamic panel data. $^{10}$

We use the estimated VAR system to extract information about the role of news. To identify the structural shocks, we assume that the reduced-form innovations and the structural shocks follow a linear relationship,

$$
\left[\begin{array}{l}
u_{1, t} \\
u_{2, t}
\end{array}\right]=\Omega\left[\begin{array}{l}
e_{1, t} \\
e_{2, t}
\end{array}\right],
$$

where $\Omega$ is a matrix of coefficients. Note that equation (1) is a special case of our VAR under our assumed structural relationships. As is well known in the literature, it is not possible to identify all the elements in $\Omega$ using only information from the reduced-form estimates. Our identification strategy assumes that news shocks cannot affect productivity contemporaneously. In this way, we assume that element $\Omega_{12}=0$. As is usual, we also assume that the structural shocks have unit variance. These restrictions are sufficient to identify the effects of news shocks in our empirical model.

Figure 2 shows the impulse-response functions of the estimated VAR to news and productivity shocks. The left panel shows the response of the EMBI+ spread to each shock, and similarly, the right panel shows the responses of labor productivity. The dashed lines represent 95 percent confidence bands. In both cases we show the effects of news and current productivity shocks that have a negative impact on productivity. As shown in the left plot, both negative shocks increase the EMBI+ spread in emerging countries, but news shocks have a substantially larger effect on

\footnotetext{
${ }^{10}$ See Uribe and Yue (2006) for a complete description. The estimation uses the procedure of Anderson and Hsiao (1981). Our results are robust to using simple OLS estimators for the panel VAR.
} 
the EMBI+ spread than contemporaneous productivity shocks. The spread response to news is stronger on impact, and decays monotonically and gradually, exhibiting some persistence. The right plot shows that news shocks have the largest impact on labor productivity between one and two years after they occur.

Figure 2: Impulse responses for the structural VAR
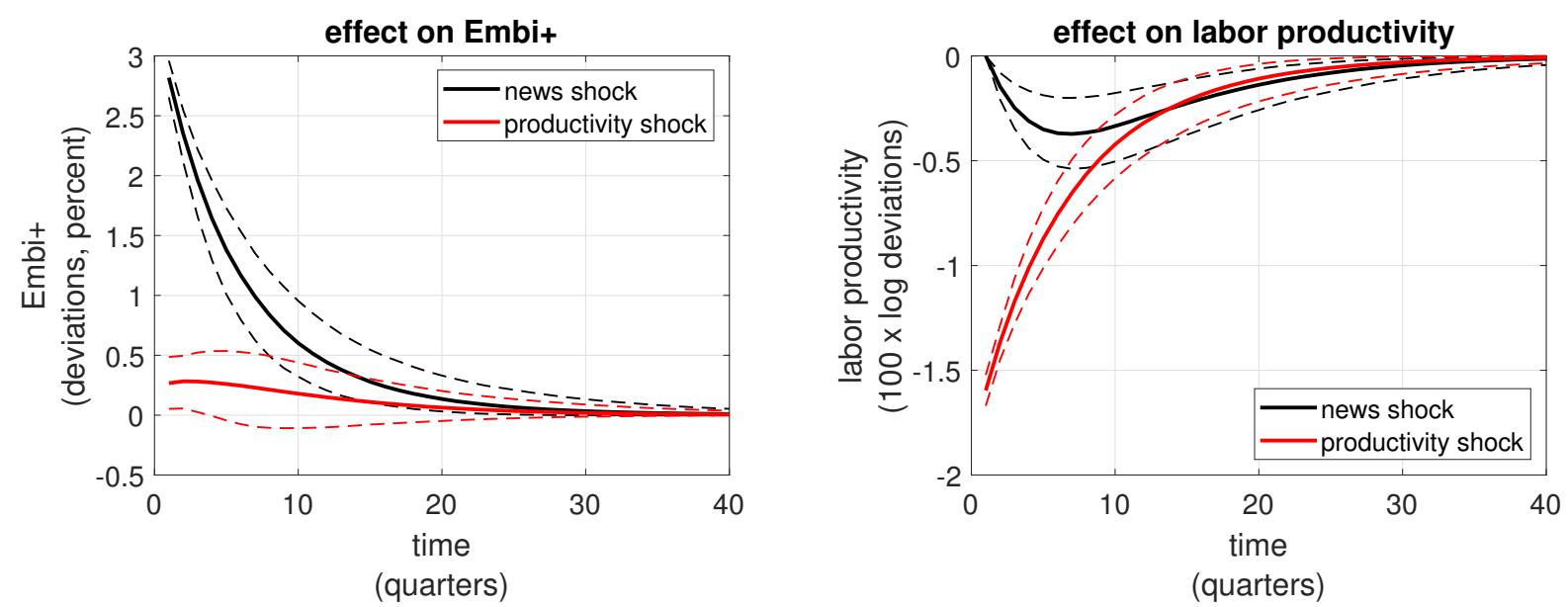

Note: Impulse response functions for the structural VAR model with short-run identification restrictions. Responses are for a one standard deviation shock. Confidence bands computed via bootstrap. Dashed lines encompass the central 95 percent of the simulations.

The magnitude of the effects is different for the two types of shocks. Table 1 shows the variance decomposition at different horizons. Given our identification strategy, news shocks do not contribute to the variance of productivity one quarter ahead. However, they are a source of uncertainty in the longer run, accounting for 8 percent of the forecast error variance 2 years ahead and 18 percent 10 years ahead. On the other hand, news shocks account for the bulk of the variance in the EMBI+.

We acknowledge that many papers have identified potential issues with this strategy, including, among others, Schmitt-Grohe and Uribe (2012) and Beaudry and Portier (2014). We use the findings presented above as a motivating starting point that must be complemented with a structural analysis using a model with news and risk of default. The empirical evidence just presented suggests that news shocks have a large impact on the risk of default and predict a future drop in productivity. The quantitative model of sovereign debt presented in the next section incorporates news about the direction of changes in productivity. In that model we show 
Table 1: Forecast Error Variance Decomposition

(Percent)

\begin{tabular}{lcc|cc}
\hline \hline & \multicolumn{2}{c}{ Productivity } & \multicolumn{2}{c}{ EMBI+ } \\
& Prod Shock & News Shock & Prod Shock & News Shock \\
\cline { 2 - 5 } 1 quarter & 100.00 & 0.00 & 0.90 & 99.10 \\
1 year & 97.56 & 2.44 & 1.62 & 98.38 \\
2 years & 92.24 & 7.76 & 2.49 & 97.51 \\
5 years & 83.78 & 16.22 & 3.69 & 96.31 \\
10 years & 82.19 & 17.81 & 3.91 & 96.09 \\
\hline \hline
\end{tabular}

Note: Forecast error variance decomposition for the structural VAR model with short-run identification restrictions at different horizons.

that spreads react more to news shocks than to a drop in productivity of similar magnitude. We use the model to study the role of news on debt management (i.e., level and maturity of debt) and on the term structure of spreads, and to understand why news may be an important driver of country risk dynamics, as observed in the data.

\section{Model}

\subsection{Preferences and shocks}

We build on the sovereign default setup with flexible maturity choice introduced in Sánchez et al. (2018). Time is discrete, and the small open economy receives a stochastic labor productivity shock, $A_{t}$, following a finite-state first-order Markov chain with state space $A \subset \mathbb{R}_{++}$and transition probability $\operatorname{Pr}\left(A_{t+1}=A_{i} \mid A_{t}=A_{l}\right)$. We discretize the labor productivity space into a grid with $N_{A}$ points.

In this economy there is a benevolent government that trades bonds in international credit markets to maximize the lifetime utility of the representative household. The discount factor is $\beta \in(0,1)$, and the preferences of the representative household are of CRRA form, with risk aversion $\gamma \geq 1$. We follow Mendoza and Yue (2012) and use GHH preferences (Greenwood et al., 1988). With these preferences, labor supply is not affected by actual or expected changes in 
wealth. ${ }^{11}$ Therefore, the period utility function is

$$
u(c, \ell)=\frac{1}{1-\gamma}\left(c-\frac{\ell^{1+\theta}}{1+\theta}\right)^{1-\gamma}
$$

where the parameter $\theta$ is the inverse of the Frisch elasticity. This specification implies that the labor supply is an increasing function of the wage only, $\ell_{t}=w_{t}^{1 / \theta}$. We assume that production takes place using a constant returns to scale technology that uses only labor so that $w_{t}=A_{t}$. Then, $\ell_{t}=A_{t}^{1 / \theta}$ and output is $Y_{t}=w_{t} \ell_{t}=A_{t}^{1+\frac{1}{\theta}}$.

\subsection{News}

Every period, the government receives a signal, $s \in\left\{1,2, \ldots, N_{s}\right\}$ about the realization of labor productivity for next period, where $N_{s} \leq N_{A}$ is the number of grid points for the signal. We assume that the signal corresponds to a specific change in the productivity level between the current period and the next. Specifically, there are three signals $\left(N_{s}=3\right)$ : Signal 1 corresponds to a strictly lower productivity, Signal 2 corresponds to no change in productivity, and Signal 3 corresponds to a strictly higher productivity. More formally:

$$
S\left(A^{\prime}, A\right)= \begin{cases}1, & \text { if } A^{\prime}<A \\ 2, & \text { if } A^{\prime}=A \\ 3, & \text { if } A^{\prime}>A\end{cases}
$$

The probability of realizing a signal $s$ if the future probability shock is $A_{i}$ and the current one is $A_{l}$, is given by:

$$
\operatorname{Pr}\left(s_{t}=j \mid A_{t+1}=A_{i}, A_{t}=A_{l}\right)= \begin{cases}\eta, & \text { if } j=S\left(A_{i}, A_{l}\right) \\ \frac{1-\eta}{N_{s}-1}, & \text { otherwise. }\end{cases}
$$

\footnotetext{
${ }^{11}$ We could easily generalize to other types of preferences with wealth effects on labor supply. We adopt this specification since they have been used in the literature of sovereign default (Mendoza and Yue, 2012). Moreover, Schmitt-Grohe and Uribe (2012) found that in a macroeconomic model with news shocks for the United States, estimates favor this type of preferences with no wealth effects on labor.
} 
Note that the probability of receiving a particular value of the signal depends on the current level of productivity. For instance, because of mean reversion, it is more likely to receive a signal that productivity will increase if productivity is below the mean. It can be shown that the probability of receiving a particular signal given a value of labor productivity is

$$
\operatorname{Pr}\left(s_{t}=j \mid A_{t}=A_{l}\right)=\sum_{n} \operatorname{Pr}\left(A_{t+1}=A_{n} \mid A_{t}=A_{l}\right) \operatorname{Pr}\left(s_{t}=j \mid A_{t+1}=A_{n}, A_{t}=A_{l}\right) .
$$

After some algebra, it can be shown that the forecast of the probability of receiving a productivity shock $A_{i}$ given the current productivity and the signal is

$$
\operatorname{Pr}\left(A_{t+1}=A_{i} \mid A_{t}=A_{l}, s_{t}=j\right)=\frac{\operatorname{Pr}\left(s_{t}=j \mid A_{t+1}=A_{i}, A_{t}=A_{l}\right) \operatorname{Pr}\left(A_{t+1}=A_{i} \mid A_{t}=A_{l}\right)}{\operatorname{Pr}\left(s_{t}=j \mid A_{t}=A_{l}\right)}
$$

It is also useful to describe the implied joint transition of productivity and signal, which is:

$\operatorname{Pr}\left(A_{t+1}=A_{i}, s_{t+1}=k \mid A_{t}=A_{l}, s_{t}=j\right)=\operatorname{Pr}\left(A_{t+1}=A_{i} \mid A_{t}=A_{l}, s_{t}=j\right) \operatorname{Pr}\left(s_{t+1}=k \mid A_{t+1}=A_{i}\right)$

Appendix B demonstrates how these expressions are obtained.

What does news do? News changes the probability distribution of next-period productivity given the current level of productivity. Figure 3 shows three cases of probability distribution, for current productivity at 0.945 and informative signals, $\eta=0.95$. The green line shows the unconditional probability distribution. It is the distribution of probabilities for next period's labor productivity in the absence of news. On average, labor productivity is expected to increase because of mean reversion. The blue line represents bad news. Given equation (5), this shock is not very likely, given that labor productivity is expected to increase before observing the signal. But after the bad news signal is observed, the change in the distribution is very stark, and it is much more likely that labor productivity will decrease tomorrow. Finally, the red line represents good news. Observing this signal is more likely, and the change in the distribution is less severe because, given that current productivity is low, an increase in productivity is expected with high probability even before the signal is observed. 
Figure 3: News and the probability distribution of next period productivity

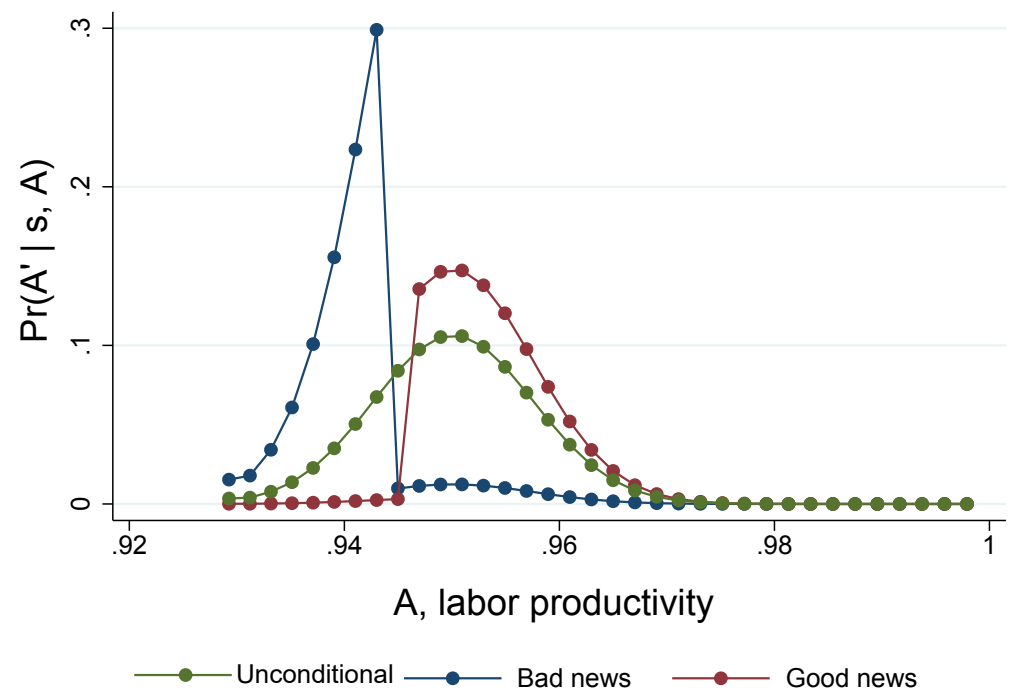

\subsection{Credit markets}

The country participates in international credit markets, where lenders are risk neutral. The country cannot commit to repaying its obligations, so given an outstanding amount of assets, $b$ (debt if $b<0$ ), it has two actions to choose from. The first option is to pay its obligations and thus keep its good credit status. Alternatively, the country may decide not to make its debt payment, i.e., default.

A default brings immediate financial autarky and a direct productivity loss to the defaulting country. After the initial default decision, the country remains in autarky for a stochastic number of periods and then returns to international debt markets but with its debt restructured. The restructuring of the debt entails a haircut and an increase in maturity. Both the haircut and the maturity extension are exogenous and calibrated to the data presented in Dvorkin et al. (2018). ${ }^{12}$

In times of good credit status, the country may face a "debt rollover" shock, $a$, where $a=0$ if the country is facing a disruption in its access to financial markets and is hence impeded from rolling over or changing its debt portfolio, and 1 otherwise. When the country experiences this sudden stop event, world financial markets cease to lend to the economy, so the country may

\footnotetext{
${ }^{12}$ Dvorkin et al. (2018) show that restructurings that look similar to the data can be endogenously obtained in a model in the tradition of Eaton and Gersovitz (1981).
} 
only choose between repaying or repudiating its obligations. Thus, the decision to default is influenced by the current level of debt and its maturity, by the country's productivity, $A$, which fluctuates exogenously over time, by the news about future productivity, by the costs of default, and by the debt rollover shock.

If the country decides not to default, it selects the maturity of the new portfolio, $m^{\prime}$, and the new debt level, $b^{\prime}$, as in Sánchez et al. (2018). The optimal choices of maturity and asset levels are influenced by the current level of productivity, the news shock, the current level of debt and its maturity, and the debt rollover shock. There is also a cost of adjusting the portfolio, which for simplicity is omitted from the equations in the main body of the paper. ${ }^{13}$

\subsection{Decision problem}

The government starts each period with its states consisting of the productivity shock, $A$; the signal about the productivity of next period, $s$; the sudden stop shock, $a$; asset level, $b$; and maturity, $m$. The government decides, among other things, whether to default on the existing debt or not:

$$
V(A, s, a, b, m)=\max \left[V^{G}(A, s, a, b, m), V^{D}(A, s, b, m)\right]
$$

where the policy function $D(A, s, a, b, m)$ is 1 if default is preferred and 0 otherwise. If the country does not receive a sudden stop shock $(a=1)$, and decides not to default, it selects the maturity of the new portfolio, $m^{\prime}$, and the debt level, $b^{\prime}$. The value in this case is:

$$
V^{G}(A, s, 1, b, m)=\max _{b^{\prime}, m^{\prime}, \ell} \frac{1}{1-\gamma}\left(c-\frac{\ell^{1+\theta}}{1+\theta}\right)^{1-\gamma}+\beta E_{A^{\prime}, s^{\prime}, a^{\prime} \mid A, s} V\left(A^{\prime}, s^{\prime}, a^{\prime}, b^{\prime}, m^{\prime}\right)
$$

subject to

$$
\begin{aligned}
& c=A \ell+b-\underbrace{q\left(A, s, b^{\prime}, m^{\prime} ; m^{\prime}\right) b^{\prime}}_{\text {issue new debt }}+\underbrace{q\left(A, s, b^{\prime}, m^{\prime} ; m-1\right) b}_{\text {retire old debt }} \\
& b^{\prime} \in \mathbb{R}_{-}, m^{\prime} \in \mathbf{M} .
\end{aligned}
$$

\footnotetext{
${ }^{13}$ We explain in the calibration section the role of this adjustment cost.
} 
In contrast, a country that receives a sudden stop shock and therefore has no access to credit markets $(a=0)$, may pay but cannot issue new debt:

$$
V^{G}(A, s, 0, b, m)=\max _{\ell} \frac{1}{1-\gamma}\left(A \ell+b-\frac{\ell^{1+\theta}}{1+\theta}\right)^{1-\gamma}+\beta E_{A^{\prime}, s^{\prime}, a^{\prime} \mid A, s} V\left(A^{\prime}, s^{\prime}, a^{\prime}, b, m-1\right) .
$$

The policy functions for the amount of debt and the maturity are $B(A, s, a, b, m)$ and $M(A, s, a, b, m)$. Notice that when a country makes only its debt payment, the policies are $B(A, s, a, b, m)=b$ and $M(A, s, a, b, m)=m-1$. It then follows that if $a=0$, it must be that $B(A, s, 0, b, m)=b$ and $M(A, s, 0, b, m)=m-1$.

Default brings immediate financial autarky for a stochastic number of periods and a direct productivity loss to the defaulting country. Formally, the value of default is:

$$
\begin{aligned}
& V^{D}(A, s, b, m)=\max _{\ell} \frac{1}{1-\gamma}\left(\min (A, \phi) \ell-\frac{\ell^{1+\theta}}{1+\theta}\right)^{1-\gamma}+ \\
&\left.\beta E_{A^{\prime}, s^{\prime}, a^{\prime} \mid A, s}\left[(1-\lambda) V^{D}\left(A^{\prime}, s^{\prime}, b, m\right)+\lambda V\left(A^{\prime}, s^{\prime}, a^{\prime}, b^{R}, m^{R}\right)\right)\right],
\end{aligned}
$$

where the parameter $\lambda$ captures the probability of reentry to international capital markets after default, and $m^{R}=m+\varrho$ is the maturity extended in restructuring and $b^{R}$ is such that the face value haircut in total debt is $(1-\varphi)$; i.e., $b^{R} \times m^{R}=\varphi \times b \times m$.

\subsection{Equilibrium bond prices}

Given the world interest rate $r$, the price of the country's debt must be consistent with zero expected discounted profits. The price of a bond of maturity $n>0$ of a country with productivity $A$, new debt $-b^{\prime}$, and maturity $m^{\prime}>0$ can be represented by

$$
\begin{aligned}
q\left(A, s, b^{\prime}, m^{\prime} ; n\right)=\frac{E_{A^{\prime}, s^{\prime}, a^{\prime} \mid A, s}}{1+r}\{ & {\left[\left(1-D\left(A^{\prime}, s^{\prime}, a^{\prime}, b^{\prime}, m^{\prime}\right)\right) \times\right.} \\
& \left.\left(1+q\left(A^{\prime}, s^{\prime}, B\left(A^{\prime}, s^{\prime}, a^{\prime}, b^{\prime}, m^{\prime}\right), M\left(A^{\prime}, s^{\prime}, a^{\prime}, b^{\prime}, m^{\prime}\right) ; n-1\right)\right)\right]+ \\
& \left.\left(D\left(A^{\prime}, s^{\prime}, a^{\prime}, b^{\prime}, m^{\prime}\right)\right)\left[q^{D}\left(A^{\prime}, s^{\prime}, b^{\prime}, m^{\prime} ; n\right)\right]\right\}
\end{aligned}
$$


where the price of debt in default is simply

$$
q^{D}\left(A, s, b^{\prime}, m^{\prime} ; n\right)=\frac{E_{A^{\prime}, s^{\prime} \mid A, s}}{1+r}\left\{(1-\lambda) q^{D}\left(A^{\prime}, s^{\prime}, b^{\prime}, m^{\prime} ; n\right)+\lambda \frac{n}{m^{\prime}} q\left(A^{\prime}, s^{\prime}, b^{R}, m^{R} ; m^{R}\right)\right\}
$$

and, as above, $\lambda$ represents the probability of restructuring and $m^{R}=m+\varrho$ is the maturity once extended in restructuring and $b^{R}$ is such that the face value haircut in total debt is $(1-\varphi)$; i.e., $b^{R} \times m^{R}=\varphi \times b \times m$.

\section{Quantitative analysis}

We solve the model numerically, calibrating most parameters based on the literature. The remaining parameters are calibrated directly to the data or chosen so that the model replicates key moments. In this section we describe the calibration strategy and compare the results with the data. As we focus on sovereign default risk, we consider sovereign bond yield spreads over risk-free debt instruments, where the spread at each maturity is the difference between the yield on a zero-coupon bond with that maturity and default risk, and the yield on a bond with the same characteristics but with negligible default risk. We present the details of the model computations in Appendix C.

\subsection{Calibration}

We calibrate the model to a yearly frequency. As shown in Table 2, households in the economy have a constant relative risk aversion (CRRA) utility with risk aversion coefficient $\gamma$, which is set at 2 , a standard value in the literature. We set the maximum possible maturity to 20 years, which is significantly larger than the maturity observed for emerging markets. ${ }^{14}$ We set the yearly risk-free interest rate to 0.042, which matches the long-run average of 10-year U.S. Treasury bonds. The parameter $\theta$, which determines the Frisch elasticity, and the parameters for the law of motion for labor productivity are computed using moments of detrended (log) real GDP per capita and (log) employment to population for Colombia and the model specification of

\footnotetext{
${ }^{14}$ Our results are robust to allowing for longer maximum maturities.
} 
the labor supply and output. In this way, we obtain $\theta=0.538$, which implies a Frisch elasticity of 1.89. This number is close to the one used by Mendoza and Yue (2012). The standard deviation of the innovation in labor productivity is set to 0.0078 and the autocorrelation to 0.9044 . These numbers, together with the value of $\theta$, replicate the autocorrelation and volatility of detrended GDP per capita for Colombia.

Following Bianchi et al. (2018), we identify 3 sudden stop episodes between 1990 and 2010 that were not related to the fundamentals in Colombia: 1994-1995 (Tequila crisis), 1998 (Russian default), and 2008 (global financial crisis) with an average duration of 1.25 years. Therefore, we calibrate the probability of a sudden stop to be 0.15 yearly, and for simplicity we consider it to be i.i.d. ${ }^{15}$ The probability of redemption following a default episode, $\lambda$, is set to 0.17 , which corresponds to a 6-year average international capital market exclusion period as documented in Richmond and Dias (2009). This includes both the average time countries spend in default and the average time countries are excluded from financial markets once their debt is restructured.

We introduce adjustment costs for changing the debt portfolio in normal times to capture issuance costs. We assume that both changes in maturity and changes in the size of yearly payments are costly. As a result, there are two parameters in the adjustment cost function, $\alpha_{1}$ and $\alpha_{2} \cdot{ }^{16}$ The parameters in the function are calibrated following Dvorkin et al. (2018) to match the cost of issuing debt on average. The curvature prevents large increases in debt and a consumption boom in the period before default, so it is calibrated to the average level of debt before default. ${ }^{17}$

We calibrate the default haircut, $(1-\varphi)$, and the extension of maturity in default, $\varrho$, such that the model replicates the average face value haircut in Cruces and Trebesch (2013), about 35 percent, and the average extension of maturity in Dvorkin et al. (2018), 3 years.

\footnotetext{
${ }^{15}$ Alternative ways of modeling exogenous variation in the availability of credit would be to add risk-averse pricing kernels, as proposed, for instance by Lizarazo (2013), or to introduce exogenous variations in the risk-free rate.

${ }^{16} \mathrm{We}$ use the following functional form for the costs of changing the debt and maturity: $\chi\left(b, m, b^{\prime}, m^{\prime}\right)=$ $\alpha_{1} \exp \left(\alpha_{2}\left(\frac{m+m^{\prime}}{2}\left|b-b^{\prime}\right|-\frac{b+b^{\prime}}{2}\left|m-m^{\prime}\right|\right)\right)-\alpha_{1}$, where $-b$ and $m$ are the level and maturity of the debt portfolio, respectively, after making the current payment, and $-b^{\prime}$ and $m^{\prime}$ are those of the newly issued debt.

${ }^{17}$ See the discussion in Hatchondo et al. (2016) about the large debt increases and the consumption boom before default. While they impose an upper limit on the spread, we prevent this behavior with the curvature of the adjustment cost function.
} 
Table 2: Calibrated parameters

\begin{tabular}{lrr}
\hline \hline Parameter & Value & Reference \\
\hline Discount factor, $\beta$ & 0.93 & Debt/output 33\% (model, 33\%) \\
Cost of default, $\phi$ & 0.95 & Default rate 2.5\% (model, 2.5\%) \\
\hline Interest rate, $r$ & 0.042 & Average 10-year U.S. yield \\
Redemption prob., $\lambda$ & 0.17 & 6 year average exclusion \\
Sudden stop prob., $p_{s}$ & 0.15 & Exogenous events as in Bianchi et al. (2018) \\
Portfolio adj. cost, $\alpha_{1}$ & 0.00005 & Average issuance costs as in Dvorkin et al. (2018) \\
Portfolio adj. cost, $\alpha_{2}$ & 20 & Limit Debt/GDP increases before default \\
Risk aversion, $\gamma$ & 2 & Usual value in the literature \\
Labor prod. shock std, $\sigma_{A}$ & 0.0078 & Aggregate GDP data for Colombia \\
Labor prod., $\rho_{A}$ & 0.904 & Aggregate GDP data for Colombia \\
Inverse of Frisch elasticity, $\theta$ & 0.54 & Aggregate employment data for Colombia \\
Precision of news, $\eta$ & 0.95 & As in Durdu et al. (2013) \\
Face value haircut, $(1-\varphi)$ & 0.35 & As in Cruces and Trebesch (2013) \\
Maturity extension, $\varrho$ & 3 & As in Dvorkin et al. (2018) \\
\hline \hline
\end{tabular}

As is standard in the literature, $\beta$ and $\phi$ are calibrated to replicate the debt-to-output ratio and the default rate. We calibrate these parameters to obtain a default rate of $2.5 \%$ and a debt-to-output ratio of $33 \%$. We solve the model using the method developed in Dvorkin et al. (2018). See Appendix C for further details.

\subsection{Model validation}

The non-targeted moments of interest generated by the model and the corresponding empirical statistics for a set of key emerging market economies are shown in Table 3. The model captures very well the average maturity and duration observed in the data, as well as their procyclical behavior. The table also provides information about sovereign interest rate spreads at different maturities. Consistent with the sample data, on average the 1-year spread is below the 10-year spread, i.e., the term premium tends to be positive. The size of the premium is about 115 basis points in the model, also in line with the data. Finally, interest rate spreads for all debt maturities tend to behave countercyclically, i.e., higher spreads are observed in bad times, both in the calibrated model and in the data. 
Table 3: Fit of non-targeted moments

\begin{tabular}{lcccc}
\hline \hline Moments & Model & Brazil & Colombia & Turkey \\
\hline$\sigma(\log (c)) / \sigma(\log (y))$ & 0.97 & 1.15 & 1.15 & 1.08 \\
$\sigma(\log (T B / y)) / \sigma(\log (y))$ & 0.20 & 0.57 & 1.36 & 0.34 \\
$\rho(\log (c), \log (y))$ & 0.88 & 0.75 & 0.90 & 0.92 \\
$\rho(T B / y, \log (y))$ & 0.21 & 0.16 & -0.08 & 0.05 \\
Maturity & 9.87 & 5.98 & 9.69 & 7.80 \\
Duration & 4.99 & 3.41 & 5.42 & 5.23 \\
Duration (good times) & 5.16 & 3.58 & 5.82 & 5.74 \\
Duration (bad times) & 4.81 & 3.18 & 4.26 & 3.76 \\
$\rho($ dur, $\log (y))$ & 0.11 & 0.69 & 0.93 & 0.69 \\
1-year spread & 0.07 & 1.01 & 0.96 & 1.53 \\
1-year spread (good times) & 0.00 & 0.73 & 0.80 & 1.65 \\
1-year spread (bad times) & 0.50 & 1.78 & 1.42 & 1.52 \\
10-year spread & 1.22 & 2.19 & 2.33 & 2.41 \\
10-year spread (good times) & 0.69 & 1.61 & 1.43 & 2.25 \\
10-year spread (bad times) & 1.93 & 7.08 & 4.32 & 2.50 \\
\hline \hline
\end{tabular}

Source: See Appendix A.

While the statistics in Table 3 show that the model describes well the average and cyclical behavior of debt maturity, duration and interest rates spreads at different maturities, Figure 4 illustrates that the model also performs in line with the data around an extreme debt distress event, i.e., a sovereign default. The upper left plot suggests that following a sharp drop in output, the economy defaults and then economic activity recovers more gradually. The pattern is similar to the findings in Mendoza and Yue (2012). As shown in the upper right panel, the debt-to-GDP ratio increases prior to the default, especially in the year going into the episode, consistent with the collapse in output. Consistent with the lower output and the increasingly heavy debt burden faced by the economy, the short-term (1-year) interest rate spreads sharply increase before the event and retrace afterwards. In contrast, debt duration decreases as the economy approaches default, and increases after the event. 
Figure 4: Behavior around default
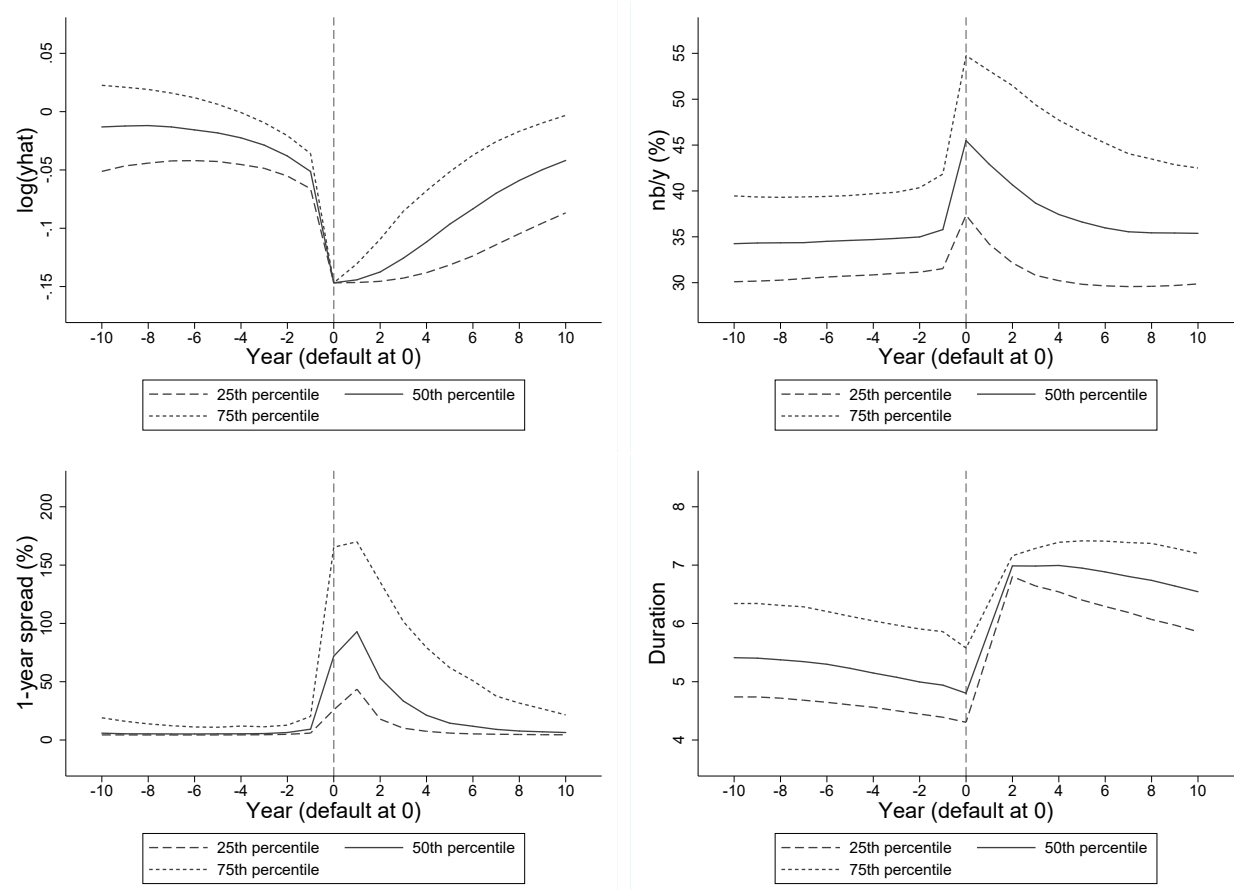

\subsection{Model mechanics}

The mechanics of the model can be grasped by looking at Table 4. The table contains linear regressions of key variables on income, debt, and news. The regressions are performed on data simulated with the model. An advantage of using simulated data is that we capture the shape of the policy functions around the values of state variables that occur more frequently in equilibrium.

The top panel shows regressions using all observations in the simulation, and the lower panel restricts the attention to economies with higher risk of default (selected on low income). The first three columns of the top panel show that maturity, duration, and borrowing are increasing in income and decreasing in current debt. The next two columns show that as income increases, both the 1-year and the 10-year spread decrease, and the change is such that the term premium increases (the positive slope of the spread curve is higher). The opposite result is obtained as debt increases: both the 1-year and the 10-year spread increase and the term premium decreases. The effect of good news and bad news is exactly the opposite. Bad (good) news decreases (increases) maturity, duration, and borrowing. Bad (good) news also increases (decreases) the 1-year and 
the 10-year spreads and reduces (raises) the term premium.

Table 4: The effects of news on selected model variables

\begin{tabular}{|c|c|c|c|c|c|c|}
\hline & \multicolumn{6}{|c|}{ All income levels } \\
\hline & $\begin{array}{c}\text { Chg log } \\
\text { maturity } \\
\text { (1) }\end{array}$ & $\begin{array}{c}\text { Chg log } \\
\text { duration } \\
(2)\end{array}$ & $\begin{array}{c}\text { Chg log } \\
\text { debt } \\
(3)\end{array}$ & $\begin{array}{c}\text { 1yr yield } \\
(4)\end{array}$ & $\begin{array}{c}\text { 10yr yield } \\
(5)\end{array}$ & $\begin{array}{c}\text { Term } \\
\text { premium } \\
(6)\end{array}$ \\
\hline $\log$ GDP & 0.151 & 0.205 & 0.137 & -0.306 & -0.879 & 0.259 \\
\hline $\log$ Debt & -0.296 & -0.305 & -0.138 & 0.178 & 0.567 & -0.147 \\
\hline dummy(good news) & 0.034 & 0.156 & 0.343 & -0.113 & -0.165 & 0.106 \\
\hline \multirow[t]{3}{*}{ dummy(bad news) } & -0.053 & -0.182 & -0.421 & 0.104 & 0.214 & -0.094 \\
\hline & \multicolumn{6}{|c|}{ Conditional on low income levels } \\
\hline & $\begin{array}{l}\text { Chg log } \\
\text { maturity } \\
(1)\end{array}$ & $\begin{array}{c}\text { Chg log } \\
\text { duration } \\
(2)\end{array}$ & $\begin{array}{c}\text { Chg log } \\
\text { debt } \\
(3)\end{array}$ & $\begin{array}{c}\text { 1yr yield } \\
(4)\end{array}$ & $\begin{array}{c}\text { 10yr yield } \\
(5)\end{array}$ & $\begin{array}{c}\text { Term } \\
\text { premium } \\
(6)\end{array}$ \\
\hline $\log$ GDP & -0.083 & 0.002 & -0.291 & -0.332 & -0.722 & 0.301 \\
\hline $\log$ Debt & -0.208 & -0.235 & 0.135 & 0.194 & 0.631 & -0.164 \\
\hline dummy(good news) & 0.022 & 0.168 & -0.036 & -0.111 & -0.208 & 0.103 \\
\hline dummy(bad news) & 0.055 & -0.121 & -0.021 & 0.147 & 0.238 & -0.138 \\
\hline
\end{tabular}

Note: Standardized regression coefficients using model-simulated data.

The bottom panel of Table 4 shows the same regressions conditional on lower income, generally associated to higher default risk. Some of the mechanics are different because in this situation countries are basically trying to avoid default. The behavior of spreads and the term premium is the same as before, but the choice of debt maturity differs. As income increases, countries choose to decrease maturity slightly, and reduce borrowing significantly, a strategy consistent with the attempt to avoid default. Starting from the same situation of financial distress, an increase in debt triggers a reduction in maturity as before, but now the change in borrowing is positive, as expected of a country that must rollover more debt. The final difference is that bad news in this situation generates an increase in maturity. Starting from a situation of financial distress, receiving bad news about tomorrow can make things very difficult, as we show below. Increasing 
maturity is a way of making the repayment easier tomorrow, and of reducing the risk of default.

\section{$5 \quad$ Bad news and sovereign debt crises}

The analysis in this section highlights that bad news can generate a sovereign debt crisis by looking first at the policy functions, and then by presenting impulse responses similar to the ones estimated in Section 2.

\subsection{Policy function analysis}

To gain insight into how the effect of news depends on debt maturity, Figure 5 shows default regions for good and bad news for 5- and 10-year maturity bonds. The upper left plot shows the default region (red area) for different values of the labor productivity and the face value of debt under good news for an economy with debt maturity of 5 years, the upper middle plot shows the same for bad news, and the upper right plot shows the difference between these two plots, i.e., the difference in the default probability due to a shift from good to bad news.

The figure suggests that in our model, countries with more debt and lower productivity choose to default. Also, as the top three plots show, a bad signal is associated to a larger default region than a good signal. The broad red band in the right plot shows that the default probability increases dramatically for several states of the economy. Given debt, maturity, and productivity, the realization of bad news changes the country's decision from repayment to default. This suggests that an economy near its default threshold may experience an important increase in its sovereign yield spreads. As it will be shown below, this is due mostly to the lower expected productivity following a bad news shock, and not to the borrowing choices of the government.

The lower plots present the default region under good and bad news when debt maturity is 10 years. First, they show that a longer maturity is associated with a smaller default region for any given news signal. Moreover, as illustrated in the lower right plot, the shift from good to bad news increases the size of the default region, but to a much lesser extent compared to the economy with the shorter (5-year) debt maturity. Therefore, our results indicate that news 
has a stronger impact on the probability of default when debt maturity is shorter. Intuitively, a shorter maturity leaves the economy more exposed to increasing interest rates, so the probability of default will be more sensitive to any given news about future fundamentals.

Figure 5: Default regions and news

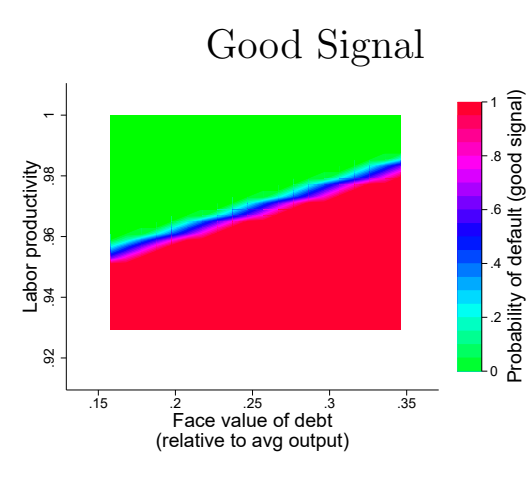

Good Signal

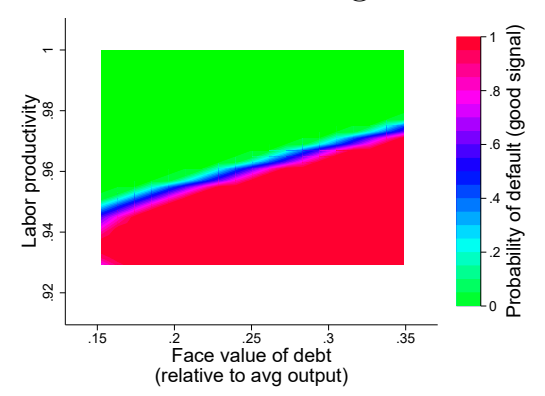

Maturity 5 years
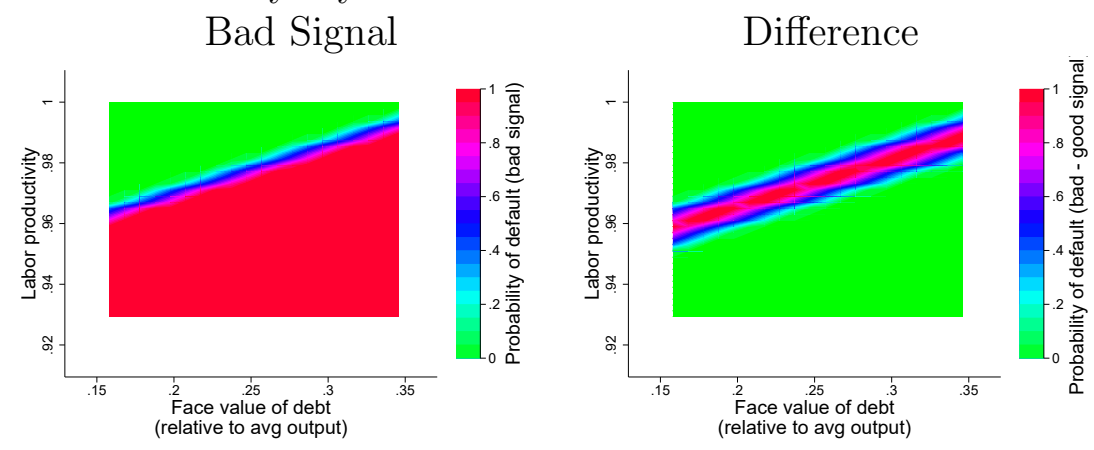

Maturity 10 years

Bad Signal

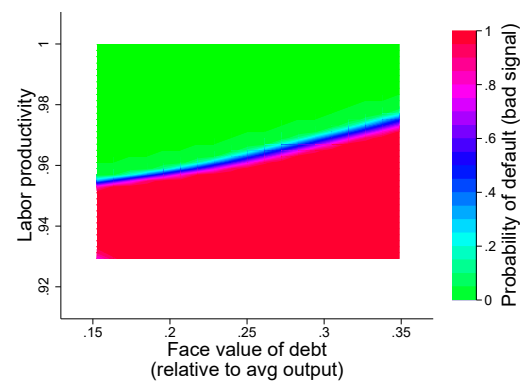

Difference

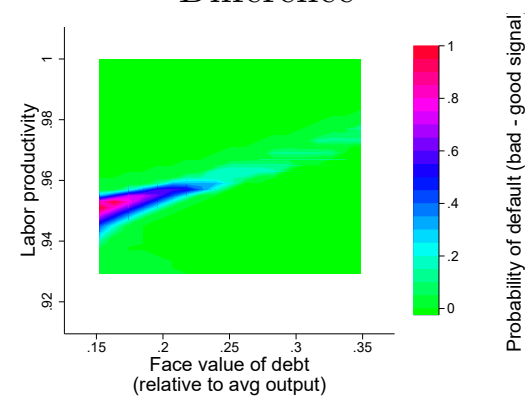

\subsection{Impulse responses}

To assess the debt pricing implications of the differential impact of news conditional on debt and maturity, Figure 6 presents the model impulse responses for changes in productivity and news of similar magnitude in terms of their effect on output. In these cases, we select an economy with the following state: a maturity of 8 years, a debt of $30 \%$ of average output, and a productivity of 0.99 ( $1 \%$ below average). In terms of the previous figure, this is an economy well within the green area initially. This state is meant to represent an economy that experienced some bad shock realizations in the past, and that is not immediately defaulting on its debt but may be 
particularly sensitive to adverse shocks.

We focus on bad news and bad productivity realizations. The dashed line on the upper left plot shows that while a bad productivity shock is associated to an immediate drop in labor productivity, bad news about future productivity leads to a similar drop in labor productivity but the effect occurs a year later, and both paths are about the same going forward. The accumulated lost income is almost the same in both cases. To the contrary, the effect of these shocks on some key variables is quite different.

Debt falls one year after both shocks, declining more for the news shock, while debt duration also declines for both on impact before recovering. In the longer run, duration seems to track the path of income. The key impulse responses are those for yields, and they are presented in the lower panels of the figure. The lower left panel shows that 1-year spreads increase dramatically (almost 5 percentage points) on impact following a bad news shock, while they only increase modestly (less than one percentage point) immediately after a bad output shock. Meanwhile, as shown in the low middle panel, 10-year spreads increase by a lower order of magnitude in response to both shocks, and the response is similar for both (about 0.5 and 0.7 percentage points for output and news, respectively). As a result, as shown in the low right plot, the term premium declines by about 4 percentage points under bad news, while it only edges down by less than a percentage point following a bad output shock.

To better understand this result, one must consider that a bad output realization occurs at the same time as a news shock. In the results above, we average across many realizations to weight appropriately according to the probability of occurrence of news shocks. The red dashed lines in Figure 7 show the impulse responses to a bad productivity shock conditional on the realization of the news shock. In the first column of plots we show the realization of a bad productivity shock that is accompanied by bad news. The middle column corresponds to a bad productivity shock together with a signal that productivity will not change. Finally, in the third column a bad productivity shock is accompanied by good news. The top plots show the evolution of productivity. The second row shows the evolution of the 1-year spread. The third and fourth rows show the distribution of future productivity and the default probability in the next period as a function of productivity, respectively. 
Figure 6: Impulse responses in the model
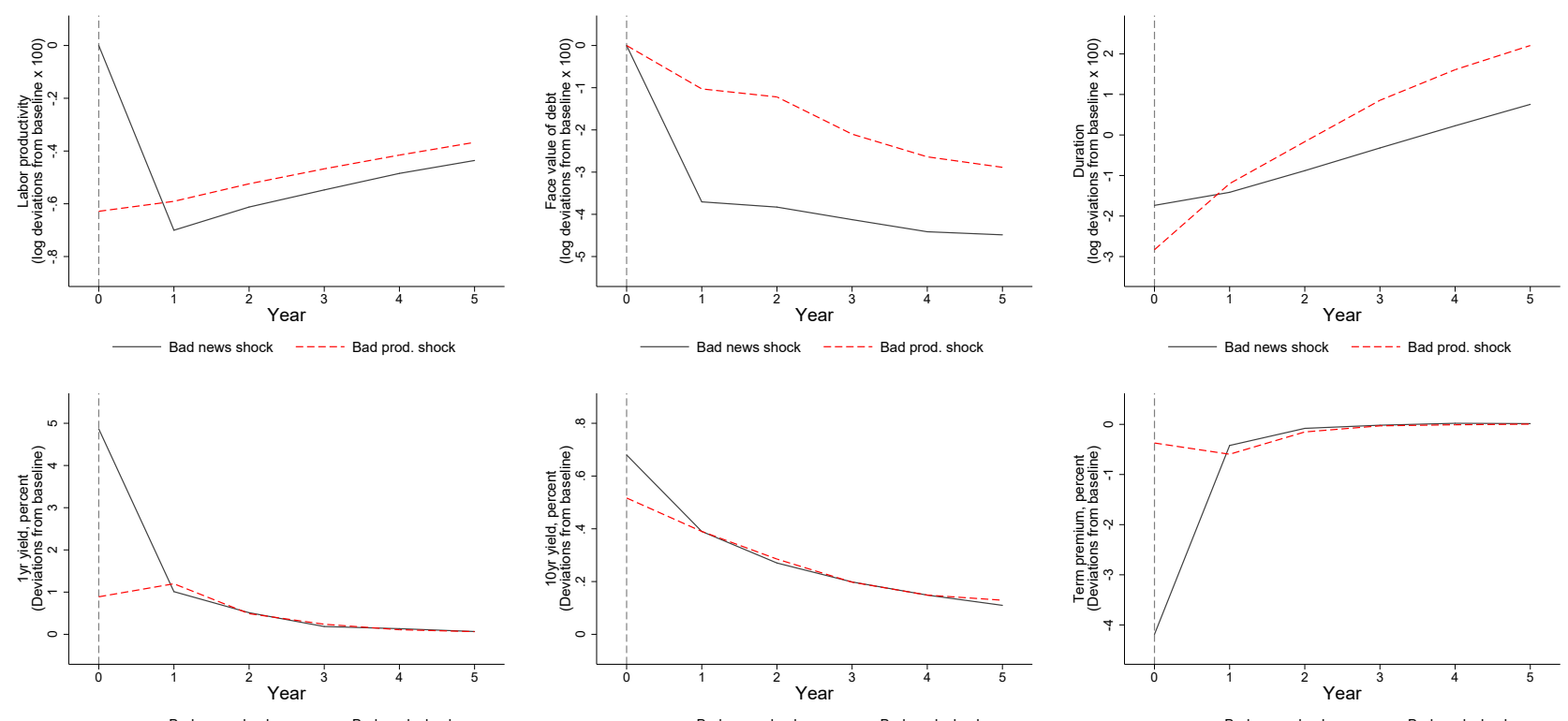

Note: The Figures are computed using simulated data from the model given a common initial state. They show the response of model variables to a bad news shock or to a bad productivity shock at period 0 of similar cumulative impact on productivity. We average simulations over all other shocks in the different periods. The response is computed in deviations from a benchmark case where we take averages over all realizations of shocks. The initial state has a maturity of 8 years, a debt of $30 \%$ of average output and a productivity of 0.99 . 
The result of a stronger response to news than to a current productivity shock is overturned only when bad output is accompanied by bad news. In that case, it is not surprising that the yields react more to the productivity shock, because there are in fact two contemporaneous negative shocks affecting the economy: bad news and lower productivity. In this scenario, the response path for the productivity shock is always below the response path in the situation with only bad news. Importantly, note that the simultaneous occurrence of these two shocks is very rare, given that the initial value of productivity is lower than the average and that our model features mean-reversion in productivity.

In the second and third columns, the 1-year yield reacts more to bad news than to bad productivity. In the middle case (second column), the bad realization of productivity is accompanied by the signal that productivity will not change next period. This is illustrated in the top middle plot, where the red dashed line is almost constant between periods 0 and $1 .{ }^{18}$ In this case, the 1-year spread actually decreases by almost 100 basis points. In the third column, the bad productivity realization is accompanied by a signal of future positive growth in productivity and, as a consequence, the 1-year yield decreases even more as the future probability of default drops sharply.

The third row shows the distribution of future productivity. Note that the documented larger response of the 1-year yield to the shock (to either bad news or lower productivity) is in line with the distribution of future productivity for this shock having more mass on the left tail. In column (a) the red dashed line corresponds to a bad productivity shock that occurred together with bad news, so that the probability distribution is shifted to the left, in line with the higher spread in the second row. Recall that the realization of these combination of shocks is unlikely. The plots in columns (b) and (c) represent more likely realizations of the shocks, as they correspond to the realization of a bad productivity shock together with news about no change or new of increasing productivity, respectively. In these two cases, there is more mass of the probability distribution on the left for the case of bad news (black line). Therefore, in those two plots the spread (second row) is higher in the case of the bad news shock.

\footnotetext{
${ }^{18}$ It is actually slightly decreasing because these impulse responses are net of the average evolution of the economy starting from the same point, which has productivity increasing back toward the mean value.
} 
Figure 7: Impulse responses in the model conditional on different initial news shocks
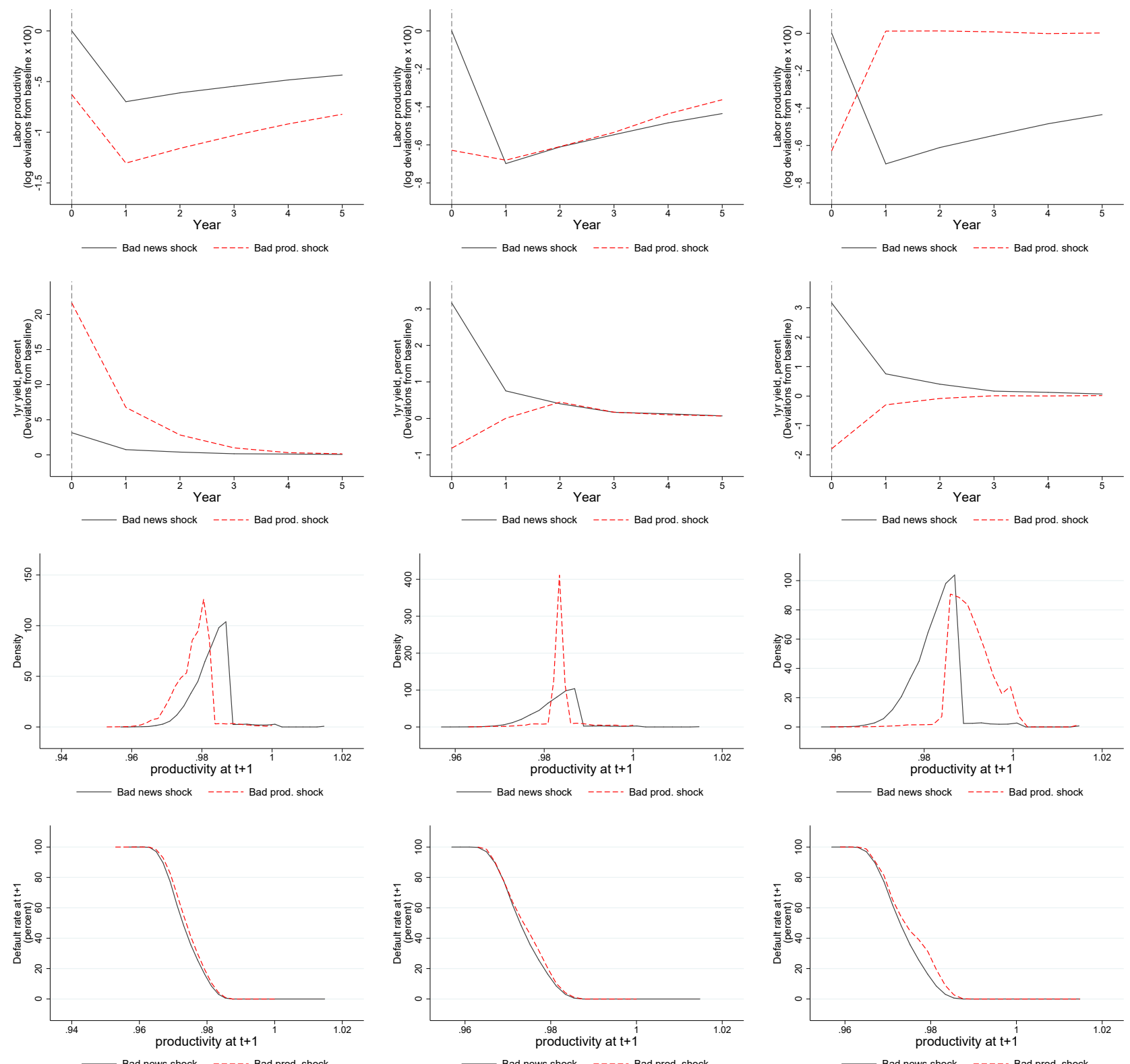

(a)

(b)

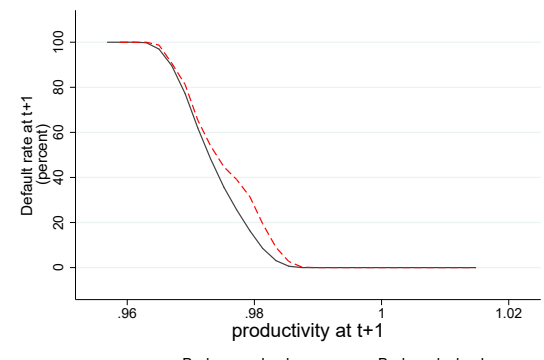

(c)

Note: The Figures are computed using simulated data from the model given a common initial state. They show the response of model variables to a bad news shock or to a bad productivity shock compounded with a news shock at period 0 . The response is computed in deviations from a benchmark case where we take averages over all realizations of shocks. The initial state has a maturity of 8 years, a debt of $30 \%$ of average output and a productivity of 0.99. Figures in column (a) display the effects of a bad news shock vs. the effects of a bad productivity shock that is accompanied by a bad news shock. Similarly, Figures in column (b) display the effects of a bad news shock vs. the effects of a bad productivity shock that is accompanied by a news shock of no-change in future productivity. Finally, Figures in column (c) display the effects of a bad news shock vs. the effects of a bad productivity shock that is accompanied by a good news shock. Default rate functions are means over simulations of possible shocks at $t+1$ and smoothed. 
In the bottom panel we disentangle the reason for the different behavior of the spread. We ask: Is that behavior due to the government debt management choices $\left(b^{\prime}, n^{\prime}\right)$ after observing the shock? Or is it due to the differences in the probability distribution for future productivity just discussed? To answer these questions, we plot the default probability policy function in period 1 as a function of the productivity that period $\left(A^{\prime}\right)$ for the choices of $b^{\prime}$ and $n^{\prime}$ made after the realization of the alternative shocks in period $0 .{ }^{19}$ By conditioning on $A^{\prime}$ we are effectively shutting down the role of the probability distribution over $A^{\prime}$. Since we find that this default probability only differs slightly across cases and shocks, we are able to conclude that the different reaction of the yields to shocks is not due to different choices made by the borrower, but to changes in the distribution of future productivity across these cases.

Another way to see this result is that the default probability at period 0 is the weighted average of the function in the bottom row, where the weights for each $A^{\prime}$ are given by the probability distribution in the third row. In these terms, our question can be rephrased as: Is the difference driven by the difference in the weights for each $A^{\prime}$, or in the difference in the default policy function conditional on $A^{\prime}$ ? While the weights capture changes in expectations about future productivity, the default policy function captures changes in the government debt management. As the difference between the red and black lines presented in the bottom row of the figure are minimal in three cases, the answer to the question above is that the larger reaction to a news shock is due to changes in expectations.

\section{The role of the precision of news}

In the previous sections we have shown that the calibrated model with news about future fundamentals captures well the average moments and the default dynamics observed in the data. In this section we highlight the role of the precision of news for the behavior of some key debt variables. To the best of our knowledge, Durdu et al. (2013) is the only other paper performing a comparison of economies with different news precision in a quantitative model with endoge-

\footnotetext{
${ }^{19}$ Note that the default policy function is actually a probability because we compute it taking averages over sudden stop shocks and news shocks at $t+1$, and also taking expectations over the taste shocks that we use to smooth the problem, as in Dvorkin et al. (2018).
} 
nous default risk. The analysis in this section complements their work showing how duration, maturity, and the term structure of interest rates are affected by the precision of news.

Table 5 shows the main moments generated by the model for different news precision levels. The first column represents the moments of the model with a lower news precision signal. The precision is higher as we move to the second and third columns. As the precision of the news on future labor productivity increases, the country experiences a decline in the sovereign default rate, while the country's debt-income ratio remains largely unchanged, i.e., the country becomes more efficient at managing its debt.

Table 5: The Role of the Precision of News

\begin{tabular}{|c|c|c|c|}
\hline \multirow[t]{2}{*}{ Moment } & \multicolumn{3}{|c|}{ Signal precision, $\eta$} \\
\hline & 0.6 & 0.8 & 0.95 \\
\hline Default (\%) & 2.81 & 2.56 & 2.46 \\
\hline Value of debt / Income & 24.23 & 24.02 & 24.40 \\
\hline Debt $\times$ Maturity/Income & 33.53 & 32.60 & 32.94 \\
\hline Maturity & 10.90 & 10.14 & 9.87 \\
\hline Duration & 5.41 & 5.11 & 4.99 \\
\hline Duration (good times) & 5.44 & 5.21 & 5.16 \\
\hline Duration (bad times) & 5.42 & 5.01 & 4.81 \\
\hline$\rho(d u r, \log (y))$ & 0.01 & 0.07 & 0.11 \\
\hline 1-year spread & 0.17 & 0.13 & 0.07 \\
\hline 1-year spread (good times) & 0.00 & 0.00 & 0.00 \\
\hline 1-year spread (bad times) & 1.46 & 0.98 & 0.50 \\
\hline 10-year spread & 1.45 & 1.28 & 1.22 \\
\hline 10-year spread (good times) & 0.75 & 0.70 & 0.69 \\
\hline 10-year spread (bad times) & 2.42 & 2.09 & 1.93 \\
\hline$\sigma(\log (c)) / \sigma(\log (y))$ & 0.96 & 0.97 & 0.97 \\
\hline$\sigma(\log (T B / y)) / \sigma(\log (y))$ & 0.16 & 0.18 & 0.20 \\
\hline$\rho(\log (c), \log (y))$ & 0.88 & 0.88 & 0.88 \\
\hline$\rho(T B / y, \log (y))$ & 0.21 & 0.20 & 0.21 \\
\hline
\end{tabular}

The debt maturity and duration in the economy also decrease with the higher news precision, and this effect, illustrated for duration in good and bad times, is largely attributable to a decline during bad times. The correlation between duration and output is moderate, but increases noticeably as the signal becomes more informative, suggesting that while the better-informed country is not necessarily changing its total debt, it is optimally changing its maturity profile, i.e., the country optimizes by changing its debt composition rather than its overall amount. 
Consistent with the changes in the debt profile just described, spreads for 1-year sovereign bond yields in bad times decline substantially, from 146 basis points to 50 basis points, i.e., they are about one third of the original one. The 10-year spreads also decrease especially in bad times, but the decline, while noticeable (from 242 to 193 basis points), is nowhere near the drop observed in 1-year spreads. The lower default rates and the reduced maturity and spreads in bad times also indicate that more precise news allows the country to improve its debt management over the business cycle.

Since the emphasis of the current study is also on the dynamics following news shocks around financial crisis, in Figure 8 we present the effect of changing the precision of news on the impulse responses to news shocks. In particular, the impulse responses presented earlier are replicated for three values of precision, $\eta=\{0.6,0.8,0.95\}$, consistent with the precision levels depicted in Table 5. First, in the top left panel of the figure, we show the path of labor productivity over 5 years following a negative news shock. As the precision of news decreases, a bad news shock has a lower impact on future labor productivity. Consistent with this effect, all the other variables respond less to bad news when the precision is lower. At the lower precision level, i.e., when $\eta=0.6$, the effect of the decrease in debt for bad news almost disappears. Similarly, the effect on the 1-year yield decreases from almost 500 basis points to slightly more than 100 basis points and, mostly as a consequence of this, the effect on the term premium is also significantly smaller-from 400 basis points to 100 basis points. 
Figure 8: Impulse responses in the model for different precision of news
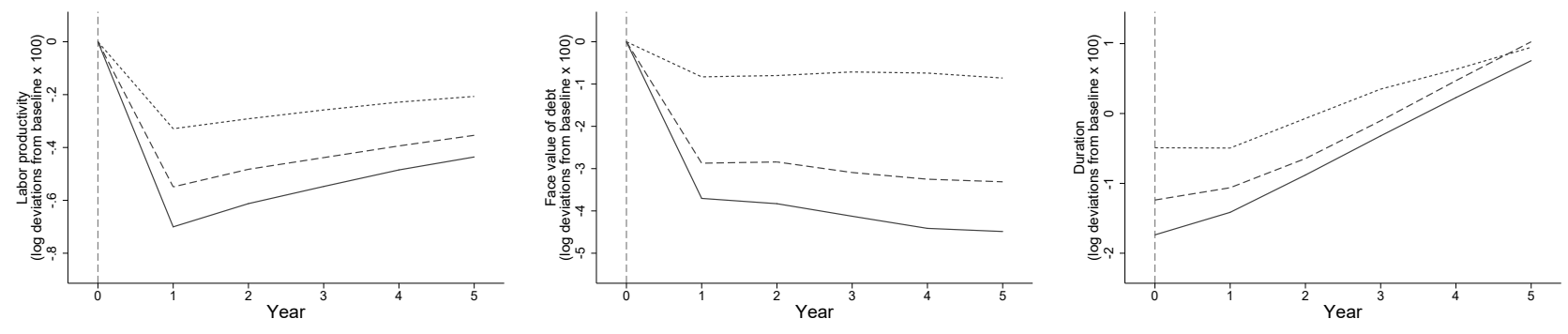

$\eta=0.6 \quad----\eta=0.8 \quad \eta=0.95$ (baseline)
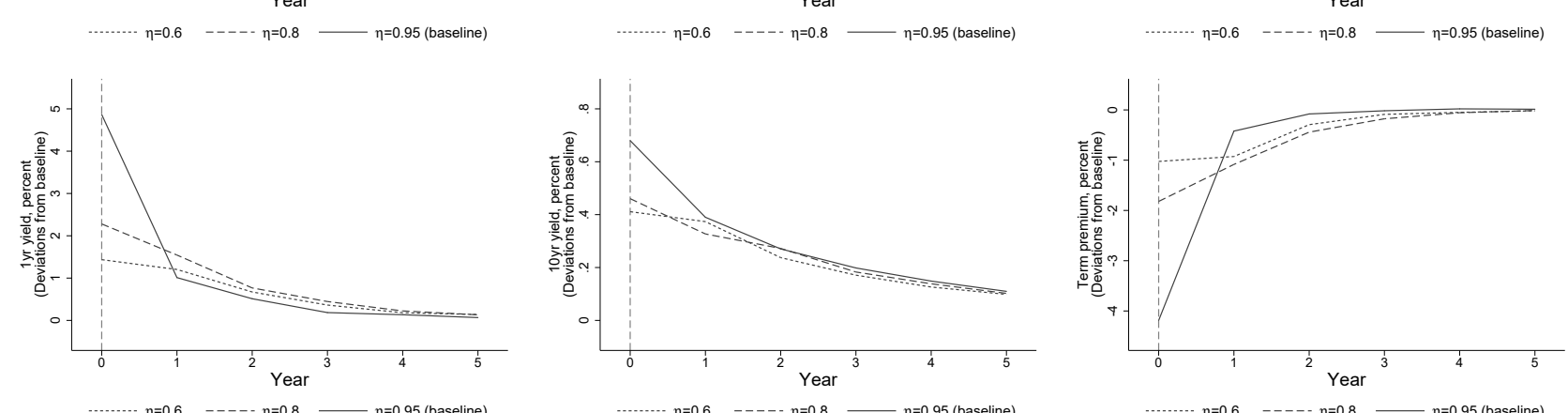

Note: The Figures are computed using simulated data from the model given a common initial state. They show the response of model variables to a bad news shock under different values of the precision parameter $\eta$. We average simulations over all other shocks in the different periods. The response is computed in deviations from a benchmark case, where we take averages over all realizations of shocks. Since we recompute the model for each value of $\eta$, the baseline differs across cases. The initial state has a maturity of 8 years, a debt of $30 \%$ of average output, and a productivity of 0.99 . 


\section{Conclusions}

We provide empirical evidence that news about future productivity significantly affects the dynamics of sovereign yield curve spreads near a debt crisis. Estimating a panel-VAR for several emerging economies, we find that a news shock has a significantly larger contemporaneous impact on sovereign credit spreads than a comparable shock to labor productivity. We rationalize our empirical results with a quantitative model of news, sovereign debt default, and endogenous maturity. Our model also helps explain the stronger effect of news shocks when debt maturity is shorter. Finally, our model suggests that higher news precision improves sovereign debt management, as the country experiences a decline in the average default rate. Interestingly, the higher news precision is not associated with increased leverage, but instead with a shorter debt maturity profile and lower yield curve spreads. Furthermore, we find that these effects from the higher precision of news are stronger during periods of high financial stress.

\section{References}

Aguiar, M. and Gopinath, G. (2006). Defaultable debt, interest rates and the current account. Journal of International Economics, 69:64-83.

Anderson, T. W. and Hsiao, C. (1981). Estimation of dynamic models with error components. Journal of the American statistical Association, 76(375):598-606.

Arellano, C. (2008). Default Risk and Income Fluctuations in Emerging Economies. American Economic Review, 98(3):690-712.

Arellano, C. and Ramanarayanan, A. (2012). Default and the maturity structure in sovereign bonds. Journal of Political Economy, 120(2):187 - 232. 
Bai, Y., Kim, S. T., and Mihalache, G. (2014). Maturity and repayment structure of sovereign debt. Unpublished manuscript, University of Rochester.

Barsky, R. B. and Sims, E. R. (2011). News shocks and business cycles. Journal of Monetary Economics, 58(3):273-289.

Beaudry, P. and Portier, F. (2006). Stock prices, news, and economic fluctuations. American Economic Review, 96(4):1293-1307.

Beaudry, P. and Portier, F. (2014). News-Driven Business Cycles: Insights and Challenges. Journal of Economic Literature, 52(4):993-1074.

Bianchi, J., Hatchondo, J. C., and Martinez, L. (2018). International reserves and rollover risk. American Economic Review, 108(9):2629-70.

Chatterjee, S. and Eyigungor, B. (2012). Maturity, indebtedness and default risk. American Economic Review, 102(6):2674-99.

Cochrane, J. H. (1994). Permanent and transitory components of GNP and stock prices. The Quarterly Journal of Economics, 109(1):241-265.

Cruces, J. J. and Trebesch, C. (2013). Sovereign Defaults: The Price of Haircuts. American Economic Journal: Macroeconomics, 5(3):85-117.

Cuadra, G., Sánchez, J., and Sapriza, H. (2010). Fiscal Policy and Default Risk in Emerging Markets. Review of Economic Dynamics, 13(2):452-469.

Durdu, C. B., Nunes, R., and Sapriza, H. (2013). News and sovereign default risk in small open economies. Journal of International Economics, 91(1):1-17.

Dvorkin, M., Sánchez, J. M., Sapriza, H., and Yurdagul, E. (2018). Sovereign debt restructurings. Federal Reserve Bank of St. Louis - Working Paper 2018-013.

Eaton, J. and Gersovitz, M. (1981). Debt with potential repudiation: theoretical and empirical analysis. Review of Economic Studies, 48:289-309. 
Greenwood, J., Hercowitz, Z., and Huffman, G. W. (1988). Investment, capacity utilization, and the real business cycle. The American Economic Review, pages 402-417.

Hatchondo, J. C. and Martinez, L. (2009). Long-duration bonds and sovereign defaults. Journal of International Economics, 79:117-125.

Hatchondo, J. C., Martinez, L., and Sosa-Padilla, C. (2016). Debt dilution and sovereign default risk. Journal of Political Economy, 124(5):1383-1422.

Jaimovich, N. and Rebelo, S. (2008). News and business cycles in open economies. Journal of Money, Credit and Banking, 40(8):1699-1711.

Jaimovich, N. and Rebelo, S. (2009). Can news about the future drive the business cycle? American Economic Review, 99(4):1097-1118.

Kamber, G., Theodoridis, K., and Thoenissen, C. (2017). News-driven business cycles in small open economies. Journal of International Economics, 105:77 - 89.

Kurmann, A. and Otrok, C. (2013). News shocks and the slope of the term structure of interest rates. American Economic Review, 103(6):2612-32.

Levchenko, A. A. and Pandalai-Nayar, N. (2015). TFP, news, and "sentiments:" the international transmission of business cycles. Technical report, National Bureau of Economic Research.

Lizarazo, S. V. (2013). Default risk and risk averse international investors. Journal of International Economics, 89(2):317-330.

Mendoza, E. G. and Yue, V. Z. (2012). A general equilibrium model of sovereign default and business cycles. The Quarterly Journal of Economics, 127(2):889-946.

Neely, C. J. (2012). The mysterious Greek yield curve. Federal Reserve Bank of St. Louis, Economic Synopses, 2012(6).

Richmond, C. and Dias, D. (2009). Duration of capital market exclusion: An empirical investigation. Working Paper. 
Sánchez, J. M., Sapriza, H., and Yurdagul, E. (2018). Sovereign default and maturity choice. Journal of Monetary Economics, 95:72-85.

Schmitt-Grohe, S. and Uribe, M. (2012). What's news in business cycles. Econometrica, 80(6):2733-2764.

Schmitt-Grohe, S. and Uribe, M. (2018). How important are terms-of-trade shocks? International Economic Review, 59(1):85-111.

Uribe, M. and Yue, V. (2006). Country spreads and emerging countries: Who drives whom? Journal of International Economics, 69:6-36.

Yue, V. Z. (2010). Sovereign default and debt renegotiation. Journal of International Economics, 80(2):176-187.

Zeev, N. B., Pappa, E., and Vicondoa, A. (2017). Emerging economies business cycles: The role of commodity terms of trade news. Journal of International Economics, 108:368-376. 


\section{Appendix A Data sources}

- GDP per capita: We use the World Development Indicators (WDI) database provided by the World Bank (constant 2005 US\$). For the volatility and correlations, we HP filter the available data.

- Debt-to-GDP ratio: For debt-to-output ratios, we use external debt stocks (\% of GNI) from the WDI for the entire period for which we have available data on spreads and maturity.

- Consumption: For the moments on consumption, we use households' final consumption expenditure per capita (constant 2005 US\$), provided by the WDI. For the volatility and correlations, the paper follows the same approach as for the GDP per capita, by HP filtering the log consumption per capita for the entire period. We also use this variable to construct the trade balance by subtracting consumption from output.

- Maturity: We use the maturity of external debt. The data for Colombia (2001-2014) and Brazil (2005-2015) are from the HAVER database, and the data for Mexico (2007-2010) are from the OECD database.

- Duration: We use the data available in the HAVER database for the duration of debt for Colombia, as we do for the maturity for this country. This measure of duration follows the Macaulay definition, which we use for our computations in the model. For Brazil and Mexico, we compute the duration using the maturity data described above for these countries, together with the official average interest on new external debt commitments provided by the International Debt Statistics, also following the Macaulay definition.

- 1yr and 10yr Spreads: The yields are US dollar sovereign yields obtained from Bloomberg. The yield spreads are obtained by subtracting US yields from the same data source.

- EMBI+ spread: Monthly data obtained from the Global Economic Monitor of the World Bank. 
- Labor productivity: We use yearly data from the International Labor Organization. The data is in constant US dollars for the year 2010.

Duration. Similar to Hatchondo and Martinez (2009) and Sánchez et al. (2018), we use the Macaulay definition to compute the duration of a bond as a weighted sum of future promised payments:

$\frac{q\left(y, a, b_{i}, m_{i} ; 1\right)+2 \times\left(q\left(y, a, b_{i}, m_{i} ; 2\right)-q\left(y, a, b_{i}, m_{i} ; 1\right)\right)+\ldots+n \times\left(q\left(y, a, b_{i}, m_{i} ; m_{i}\right)-q\left(y, a, b_{i}, m_{i} ; m_{i}-1\right)\right)}{q\left(y, a, b_{i}, m_{i} ; m_{i}\right)}$.

Yield to maturity. Consider a country with income $y$, debt rollover shock $a$, and a debt portfolio with maturity $m$ and level $b$. The yield for a bond with maturity $n$ is

$$
Y T M\left(y, a, b_{i}, m_{i} ; n\right) \equiv\left(\frac{1}{q\left(y, a, b_{i}, m_{i} ; n\right)-q\left(y, a, b_{i}, m_{i} ; n-1\right)}\right)^{\frac{1}{n}}-1 .
$$

Then the spread for maturity $m$ is $Y T M\left(y, a, b_{i}, m_{i} ; n\right)-r$.

\section{Appendix B Transition probabilities with signals about productivity change}

First, we show how to obtain equation (5). Note that by Bayes' rule, we have

$$
\operatorname{Pr}\left(s_{t}=j \mid A_{t+1}=A_{n}, A_{t}=A_{l}\right)=\frac{\operatorname{Pr}\left(s_{t}=j, A_{t+1}=A_{n}, A_{t}=A_{l}\right)}{\operatorname{Pr}\left(A_{t+1}=A_{n}, A_{t}=A_{l}\right)},
$$

which means that

$$
\operatorname{Pr}\left(s_{t}=j, A_{t+1}=A_{n}, A_{t}=A_{l}\right)=\operatorname{Pr}\left(s_{t}=j \mid A_{t+1}=A_{n}, A_{t}=A_{l}\right) \operatorname{Pr}\left(A_{t+1}=A_{n}, A_{t}=A_{l}\right) .
$$


Summing over all possible values of $n$ we obtain

$$
\operatorname{Pr}\left(s_{t}=j, A_{t}=A_{l}\right)=\sum_{n} \operatorname{Pr}\left(s_{t}=j \mid A_{t+1}=A_{n}, A_{t}=A_{l}\right) \operatorname{Pr}\left(A_{t+1}=A_{n}, A_{t}=A_{l}\right) .
$$

Finally, notice that by Bayes' rule we have

$$
\operatorname{Pr}\left(s_{t}=j, A_{t}=A_{l}\right)=\operatorname{Pr}\left(s_{t}=j \mid A_{t}=A_{l}\right) \operatorname{Pr}\left(A_{t}=A_{l}\right)
$$

and

$$
\operatorname{Pr}\left(A_{t+1}=A_{n}, A_{t}=A_{l}\right)=\operatorname{Pr}\left(A_{t+1}=A_{n} \mid A_{t}=A_{l}\right) \operatorname{Pr}\left(A_{t}=A_{l}\right)
$$

Thus, we can plug these two expression in equation (8) to obtain equation (5) in the main text, which is

$$
\operatorname{Pr}\left(s_{t}=j \mid A_{t}=A_{l}\right)=\sum_{n} \operatorname{Pr}\left(s_{t}=j \mid A_{t+1}=A_{n}, A_{t}=A_{l}\right) \operatorname{Pr}\left(A_{t+1}=A_{n} \mid A_{t}=A_{l}\right) .
$$

Now, we show how to obtain equation (6) in the main text. As above, note that using Bayes' rule we can write

$$
\operatorname{Pr}\left(A_{t+1}=A_{i} \mid A_{t}=A_{l}, s_{t}=j\right)=\frac{\operatorname{Pr}\left(A_{t+1}=A_{i}, A_{t}=A_{l}, s_{t}=j\right)}{\operatorname{Pr}\left(A_{t}=A_{l}, s_{t}=j\right)}
$$

Using Bayes' rule again, we write the numerator as

$$
\operatorname{Pr}\left(s_{t}=j, A_{t+1}=A_{i}, A_{t}=A_{l}\right)=\operatorname{Pr}\left(s_{t}=j \mid A_{t+1}=A_{i}, A_{t}=A_{l}\right) \operatorname{Pr}\left(A_{t+1}=A_{i}, A_{t}=A_{l}\right) .
$$

Recall that using Bayes's rule,

$$
\operatorname{Pr}\left(A_{t+1}=A_{i}, A_{t}=A_{l}\right)=\operatorname{Pr}\left(A_{t+1}=A_{i} \mid A_{t}=A_{l}\right) \operatorname{Pr}\left(A_{t}=A_{l}\right),
$$


$\operatorname{Pr}\left(s_{t}=j, A_{t+1}=A_{i}, A_{t}=A_{l}\right)=\operatorname{Pr}\left(s_{t}=j \mid A_{t+1}=A_{i}, A_{t}=A_{l}\right) \operatorname{Pr}\left(A_{t+1}=A_{i} \mid A_{t}=A_{l}\right) \operatorname{Pr}\left(A_{t}=A_{l}\right)$.

Replacing in the original expression, we obtain

$\operatorname{Pr}\left(A_{t+1}=A_{i} \mid A_{t}=A_{l}, s_{t}=j\right)=\frac{\operatorname{Pr}\left(s_{t}=j \mid A_{t+1}=A_{i}, A_{t}=A_{l}\right) \operatorname{Pr}\left(A_{t+1}=A_{i} \mid A_{t}=A_{l}\right) \operatorname{Pr}\left(A_{t}=A_{l}\right)}{\operatorname{Pr}\left(A_{t}=A_{l}, s_{t}=j\right)}$.

Note that using Bayes' rule the denominator can be written as

$$
\operatorname{Pr}\left(A_{t}=A_{l}, s_{t}=j\right)=\operatorname{Pr}\left(s_{t}=j \mid A_{t}=A_{l}\right) \operatorname{Pr}\left(A_{t}=A_{l}\right)
$$

Replacing the denominator we obtain

$\operatorname{Pr}\left(A_{t+1}=A_{i} \mid A_{t}=A_{l}, s_{t}=j\right)=\frac{\operatorname{Pr}\left(s_{t}=j \mid A_{t+1}=A_{i}, A_{t}=A_{l}\right) \operatorname{Pr}\left(A_{t+1}=A_{i} \mid A_{t}=A_{l}\right) \operatorname{Pr}\left(A_{t}=A_{l}\right)}{\operatorname{Pr}\left(s_{t}=j \mid A_{t}=A_{l}\right) \operatorname{Pr}\left(A_{t}=A_{l}\right)}$.

which yields the expression in equation (6),

$$
\operatorname{Pr}\left(A_{t+1}=A_{i} \mid A_{t}=A_{l}, s_{t}=j\right)=\frac{\operatorname{Pr}\left(s_{t}=j \mid A_{t+1}=A_{i}, A_{t}=A_{l}\right) \operatorname{Pr}\left(A_{t+1}=A_{i} \mid A_{t}=A_{l}\right)}{\operatorname{Pr}\left(s_{t}=j \mid A_{t}=A_{l}\right)} .
$$

The other expression for the joint transition probability, equation (7) in the main text, can be obtained in a similar way. In particular, note that

$$
\begin{gathered}
\operatorname{Pr}\left(A_{t+1}=A_{i}, s_{t+1}=k \mid A_{t}=A_{l}, s_{t}=j\right)=\operatorname{Pr}\left(A_{t+1}=A_{i} \mid A_{t}=A_{l}, s_{t}=j\right) \times \\
\operatorname{Pr}\left(s_{t+1}=k \mid A_{t+1}=A_{i}, A_{t}=A_{l}, s_{t}=j\right) .
\end{gathered}
$$

Since with our structure of signals and shocks the probability of $s_{t+1}=k$ depends only on the value of $A_{t+1}$, this can be written as in the main text,

$\operatorname{Pr}\left(A_{t+1}=A_{i}, s_{t+1}=k \mid A_{t}=A_{l}, s_{t}=j\right)=\operatorname{Pr}\left(A_{t+1}=A_{i} \mid A_{t}=A_{l}, s_{t}=j\right) \operatorname{Pr}\left(s_{t+1}=k \mid A_{t+1}=A_{i}\right)$. 


\section{Appendix C Computational details}

We solve the model numerically using the method proposed in Dvorkin et al. (2018), which uses value function iteration on a discretized grid for debt and productivity. We use a different debt grid for each maturity $m_{i}$, evenly spaced. We use 121 points for the debt grid and 41 points for the productivity grid. We solve the policy and value functions for all points on these grids, and discrete search is conducted to find the optimal debt policy, also over these grids. The price function is solved for 41 equally-spaced points on this grid, and the implied function is linearly interpolated in the other parts of the algorithm. Since default usually happens in the steeper region of the price function, we have an uneven grid for productivity that is finer below the median income. In particular, the income grid is spread evenly over 35 points below the median income, and evenly over 5 points above the median income. We use the Tauchen method to discretize the income process.

For convergence, we use a measure of distance for the price function of debt in good standing in a given iteration that takes into account the maximum absolute distance of the prices across two iterations relative to the level of the price in a given state. We declare convergence when this error is lower than $10^{-3}$.

After solving for the policy and value functions, we run the simulations for 1500 countries (paths) for 400 years and drop the first 100 periods. The model counterparts to the empirical correlation and standard deviation statistics are averages across samples. For the first-order moments, country-specific medians are taken before averaging across countries. This is consistent with our treatment of the data. 